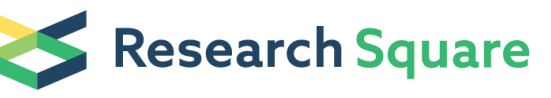

Preprints are preliminary reports that have not undergone peer review.

They should not be considered conclusive, used to inform clinical practice,

or referenced by the media as validated information.

\section{Seasonal variation of decompensated heart failure admissions and mortality rates in sub-Saharan Africa, Cameroon}

\section{Chris Nadège Nganou-Gnindjio ( $\nabla$ cn_nganou@yahoo.fr )}

University of Yaoundé 1, Faculty of Medicine and Biomedical Sciences https://orcid.org/0000-00018995-5038

\section{Anais Romanne Awah Epoupa}

Faculty of Medicine and Biomedical Sciences, University of Yaoundé I

\section{Guy Sadeu Wafeu}

Faculty of Medicine and Biomedical Sciences, University of Yaoundé I

\section{Donald Paulin Tchapmi Njeunje}

Faculty of Medicine and Biomedical Sciences, University of Yaoundé I

\section{Francky Teddy Endomba}

Faculty of Medicine and Biomedical Sciences, University of Yaoundé I

\section{Jerome Boombhi}

Faculty of Medicine and Biomedical Sciences, University of Yaoundé I

\section{Liliane Mfeukeu-Kuate}

Faculty of Medicine and Biomedical Sciences, University of Yaoundé I

\section{Sylvie Ndongo Amougou}

Faculty of Medicine and Biomedical Sciences, University of Yaoundé I

\section{Bâ Hamadou}

Faculty of Medicine and Biomedical Sciences, University of Yaoundé I

\section{Alain Patrick Menanga}

Faculty of Medicine and Biomedical Sciences, University of Yaoundé I

\section{Research article}

Keywords: decompensated heart failure, seasonal variation, Admission rate, mortality rate, Cameroon

Posted Date: July 2nd, 2020

DOI: https://doi.org/10.21203/rs.3.rs-38793/v1

License: (c) (1) This work is licensed under a Creative Commons Attribution 4.0 International License. Read Full License 
Version of Record: A version of this preprint was published at Annales de Cardiologie et d'Angéiologie on June 1st, 2021. See the published version at https://doi.org/10.1016/j.ancard.2021.04.002. 


\section{Abstract \\ Background}

Decompensated heart failure (HF) and related deaths are common in cardiology units. Epidemiological data in north hemisphere suggest higher rates during winter.

\section{Objective}

We aimed to describe the seasonal variation of decompensated HF admission and mortality rates in a country with equatorial climate.

\section{Methods}

We conducted a retrospective cross-sectional study from 2016 to 2018 in cardiology unit of the Yaoundé Central Hospital, collecting data on HF morbidity and mortality from registers and patients' files. Climate data of the corresponding period were obtained from the meteorology office of the Cameroonian ministry of transports. Analysis of variance and Chi square test were respectively used to compare the continuous and categorical data between seasons. Correlation between continuous data was assess with the Pearson correlation coefficient.

\section{Results}

Of the 1,755 patients admitted in the unit during the study period, $636(36.2 \%)$ had decompensated HF, among which 115 (18\%) died. Decompensated HF admission, mortality and lethality rates - respectively $38.2 \%, 6.7 \%$ and $17.9 \%$ - were higher during long rainy season $(p>0.05)$. We observed an inverse linear correlation between monthly temperatures and admission rate $(r=-0.301 ; p=0.070)$, lethality rate $(r=-$ $0.361 ; p=0.030)$ and mortality rate $(r=-0.385 ; p=0.020)$. There was no significant difference of the distribution of precipitating factors between seasons.

\section{Conclusion}

Decompensated HF admissions and deaths increases in rainy season where the temperature is lower. This suggest a need of effective methods to mitigate the effect of cold on cardiovascular diseases.

\section{Background}

Cardiovascular diseases (CVDs) are a global pandemic leading to about 17.9 million deaths each year worldwide, representing $31 \%$ of all global deaths [1]. Among these CVDs, heart failure (HF) which is 
characterize by the inability of the heart to pump enough blood to meet metabolic demands, affect at least 37.7 million people worldwide [2]. Its prevalence increases with age to about $10 \%$ in patients aged above 75 years [3]. In sub-Saharan Africa, HF represent $9.4-42.5 \%$ of all medical admissions, and 25.5$30 \%$ of all admissions in cardiology unit. The mortality all-cause mortality rate of hospitalized patient at one year following discharge rage from 21.9 to $57.9 \%$ [4]. Most of patients hospitalized for heart failure are presenting with signs and symptoms of congestion and fluid retention, in the context of pre-existing cardiomyopathy. A potential precipitating factor for this so-called decompensated heart failure was identified in $88.5 \%$ of patients. Among these factors are the noncompliance with diet, lack of adherence to prescribed medications, infections, arrhythmias, acute coronary ischemia, uncontrolled hypertension and other miscellaneous causes [5].

Climate and seasons variations play a role in onset and mortality of CVDs. In many countries, there is a clear seasonal pattern in mortality rates of CVDs and myocardial infarction, being higher in winter than in other seasons. Low ambient temperature, physical inactivity, air pollution and infections were the main factors associated to these variations [6]. Previous studies have described similar seasonal variations for heart failure. Highest admission and mortality rates were reported in winter. In addition, mean length of stay and median hospitalization cost were highest in winter [7]. Many hypothesis have been suggested to explain this burden of admissions in winter, among which : (i) increased cardiovascular risk due to lower physical activity; (ii) lower vitamin D synthesis linked to lower light exposition; (iii) increased blood pressure and decreased fluid lost related to lower temperature; (iv) higher pollution levels and flu-like infection frequency [8]. However, climate and meteorological parameters in northern hemisphere are different from those observed in equatorial region, and data on seasonal variation of CVDs in this later region are really scarce. This study aimed to describe variations of decompensated HF hospitalizations and mortality rates between the different seasons and the influence of meteorological parameters on these admissions and deaths in Cameroon, a sub Saharan Africa country located in the equatorial region.

\section{Methods}

\section{Study population and setting}

We conducted a retrospective cross-sectional study in cardiology department of the Yaoundé Central Hospital, including all adult patients admitted for decompensated HF between January 1st, 2016 and December 31st, 2018. The diagnosis of decompensated HF was based on signs and symptoms, and transthoracic echocardiography results, according to the 2016 European Society of Cardiology Guidelines for the diagnosis and treatment of acute and chronic heart failure [9]. Patients with incomplete files were excluded.

\section{Data collection}

Participants' data were collected from admission registers of the unit and patients' files. This included the total number of admissions for each month and year, potential precipitating factors of decompensated $H F$, survival outcome of the subject. 
We used climate data obtained from the meteorology office of the Cameroonian ministry of transports. These were the monthly data of precipitation, humidity and temperature over the period of 2016-2018. From previous geographical studies done in Yaoundé, we defined four major seasons which were the long dry season (November, December, January, February and March), the short rainy season (April and May), the short dry season (June and July) and the long rainy season (August, September and October) [10]. Rainfall index (RI) was estimated from the following formula:

$R I=P x / P m(2016-2018)$ with

$\operatorname{Pm}(2016-2018)=\sum_{x=1}^{n} \frac{p_{x}}{n}=$ average precipitation during the period of 2016 to 2018

$P x=$ Amount of precipitation in a year $\mathrm{x}$, a month $\mathrm{x}$ or a season $\mathrm{x}$.

We also defined dry and wet months as month with a RI less than one ore greater than one respectively.

\section{Statistical analysis}

Categorical data were described with number and percentages, while continuous variables were reported as mean \pm standard deviation for normally distributed data. Categorical data were compared with a Chi square test. An unpaired-sample T test was used to compare continuous variables between two groups. For comparisons of continuous variables between more than two groups, one-way Kruskal Wallis analysis of variance for nonparametric samples was used or one-way ANOVA for continuous variables, using Bonferroni correction for multiple testing. Correlation between continuous variables was assessed with the Pearson correlation coefficient. $P$ values less than 0.05 were considered statistically significant. Data analysis was performed with PASW [SPSS] (Version 20, IBM SPSS, Chicago, IL, USA).

\section{Results}

\section{Description of clinical and meteorological data}

During the study period, 1,755 patients were admitted in the cardiology unit: 636 patients (36.2\%) had decompensated HF. Overall, 238 (13.6\%) died during this period; $115(6.5 \%)$ of these deaths were related to decompensated $\mathrm{HF}$, giving a lethality rate of $18 \%$ for this pathology.

The mean of monthly average precipitations was $214.3 \pm 174.3 \mathrm{~mm}$ and the mean humidity level was $84.4 \pm 8.7 \%$. Temperatures ranged from $22.6{ }^{\circ} \mathrm{C}$ to $32{ }^{\circ} \mathrm{C}$, with a mean of $26.4 \pm 2.8^{\circ} \mathrm{C}$. The coldest months were Augusts, Septembers and Octobers - corresponding to long rainy season- with respective means of $24.2 \pm 1.7{ }^{\circ} \mathrm{C}, 23.9 \pm 1.1^{\circ} \mathrm{C}$ and $23.6 \pm 0.6^{\circ} \mathrm{C}$; while the hottest months were Januarys, Februarys and Marchs with $28.3 \pm 2.8^{\circ} \mathrm{C}, 29.2 \pm 2.7^{\circ} \mathrm{C}$ and $28.3 \pm 3.4^{\circ} \mathrm{C}$ as respective means.

\section{Seasonal variation of decompensated HF admissions and deaths}


Admission rate for decompensated HF was higher during the long rainy season (38.2\%) compare with all the other season $(36.7 \%, 33.1 \%$ and $35 \%$ respectively for long dry, short rainy and short dry seasons). We observed a similar result for mortality and lethality rates - with highest values during the long rainy season. All these differences were not statistically significant (Fig. 1). Admission rates, Lethality rates and mortality rates were respectively $38.2 \%, 21.9 \%$ and $8.2 \%$ for coolest months, $36.6 \%, 12.1 \%$ and $5.2 \%$ for hottest months: these differences were not statistically significant. Precipitating factors -identified in admitted patients- of decompensated HF were similarly distributed between the different seasons (Table 1).

Table 1

Seasonal variation of precipitating factors of decompensated HF

\begin{tabular}{|lllllll|}
\hline Precipitating factors & Number & \multicolumn{2}{l}{ Seasons } & & & p \\
\cline { 3 - 6 } & & $\begin{array}{l}\text { Long dry } \\
(\%)\end{array}$ & $\begin{array}{l}\text { Short rainy } \\
(\%)\end{array}$ & $\begin{array}{l}\text { Short dry } \\
(\%)\end{array}$ & $\begin{array}{l}\text { Long rainy } \\
(\%)\end{array}$ & \\
\hline $\begin{array}{l}\text { Medication non- } \\
\text { adherence }\end{array}$ & 121 & 25 & 33.1 & 37.5 & 28.5 & 0.888 \\
$\begin{array}{l}\text { Uncontrolled } \\
\text { hypertension }\end{array}$ & 82 & 25 & 26.8 & 17.4 & 14.3 & 0.585 \\
\hline Arrythmia & 74 & 20 & 28.1 & 12.5 & 20 & 0.285 \\
\hline $\begin{array}{l}\text { Infection } \\
\text { Anemia }\end{array}$ & 92 & 20 & 17.7 & 40.1 & 14.3 & 0.083 \\
\hline
\end{tabular}

\section{Correlation between meteorological parameters and rates}

Admission, lethality and mortality rates were inversely correlated to monthly average temperatures, with $p$ values of $0.070,0.030$ and 0.020 respectively. There was no statistically significant linear correlation between these rates and precipitations nor wet averages (Table 2).

Table 2

Correlation between admission, lethality and mortality rates, and meteorological parameters

\begin{tabular}{|llllllll}
\hline Meteorological parameters & \multicolumn{2}{l}{ Admission rate } & Lethality rate & \multicolumn{3}{c}{ Mortality rate } \\
\cline { 2 - 7 } & $\mathbf{r}^{*}$ & p value & $\mathbf{r}$ & p value & $\mathbf{r}$ & p value \\
\hline Mean temperature, ${ }^{\circ} \mathrm{C}$ & -0.301 & 0.070 & -0.361 & 0.030 & -0.385 & 0.020 \\
\hline Average precipitations, $\mathrm{mm}$ & 0.036 & 0.834 & 0.108 & 0.532 & 0.044 & 0.800 \\
\hline Wet level, \% & 0.029 & 0.867 & 0.264 & 0.119 & 0.187 & 0.275 \\
\hline${ }^{*} r=$ Pearson correlation coefficient; meteorological parameters averages and rates are monthly values. \\
\hline
\end{tabular}




\section{Discussion}

Cardiovascular diseases morbidity and mortality are increasing over time, - decompensated HF being one of these diseases - and constituted a burden for countries health systems, especially in sub Saharan Africa. Identification of factors contributing to this burden help to understand their pathophysiology, and to find right solution. Climate and meteorological parameters have been suggested as factors that affect admissions and mortality related to CVDs. We found that admission rates and mortality indicators were higher during long raining seasons (where humidity level is higher, and temperature is lower) and were inversely correlated to temperature.

Admission for decompensated HF represented $36.2 \%$ of total admissions during our study period; more than half of deaths in the cardiology unit were related to decompensated HF. Boombhi et al. observed a similar result in the same unit few years ago, with admissions rate of $30 \%$ and $33.3 \%$ respectively in 2014 and 2015 [11]. These high admission rates can be explained by the increasing rate of cardiovascular risk factors -among these risk factors are hypertension, obesity, smoking-in sub Saharan Africa; knowing that $\mathrm{HF}$ is one of the most common outcome of these risk factors [12]. Furthermore, there is a low treatment awareness, medical adherence and disease control for these CVDs. Medication nonadherence and uncontrolled hypertension were among the three most frequent precipitating factors for decompensated $\mathrm{HF}$ in our study. Therefore, more sensibilization is needed to reduce the burden of cardiovascular risk factors and thus HF burden. Mortality rate was lower in a group of patients admitted in US for HF between 2011 and 2013 - the overall mortality rate there was 3.1\% [7]. This suggest that sub-Saharan Africa health systems need more resources and capacity building to decrease HF mortality.

Admission, mortality and lethality rates were inversely correlated to the monthly mean temperature, and they seem higher during the long rainy season. This result is consistent with the result of Ansa et al., who observed a higher admission rate of heart failure during the rainy season [13]. Similar results were also observed in the north hemisphere, where higher rates of heart failure admissions were obtained during the winter - a season where temperature are lower and humidity is higher compare with other seasons [7]. The main explanation of this higher admission rate seems to be related to lower temperatures in these seasons, through various mechanism. Exposition to cold increases the sympathetic and renin angiotensin - aldosterone systems activities, leading to higher heart rate, peripherical vascular resistance and blood pressure. This exposition also decreases vasodilator effect of azote monoxide. All these effects increase heart post charge and reduce the cardiac output, resulting in higher probability of decompensation of pre-existing HF[14]. Patient's education must therefore emphasize on the need of more attention to the respect of therapeutic recommendations during cold periods like rainy seasons. Health workers and stakeholders must also be aware of this increase of needs in cardiology unit during rainy seasons.

The higher mortality rate observed during the rainy season may also be explained by external factors to the patient like the availability of heath human resources in hospitals during rainy seasons, especially in low and middle incomes countries like Cameroon. Most of the health worker in our context doesn't own a 
private car which can permit them to get at work on time when there is rain. The health care workforce availability may thus be reduced during rainy seasons, leading to higher mortality rates as it have been showed in other context [15].

Our study may have underestimated the real burden of decompensated HF, as it was a hospital-based study. In our country, patients recourse to other therapeutic means like traditional healer, prayers and selfmedication. Another limit is that autopsy wasn't perform for death patient, and they may be other death causes for our patient that HF.

\section{Conclusion}

Decompensated HF admission and mortality rates remain high in sub Saharan Africa. Rainy season is the period where most decompensation and deaths occur, and this may be related to lower temperatures in that season. However, external factors like availability of health work force during the rainy period may also play a role in this higher mortality during rainy season. Effective methods to mitigate the effect of cold on cardiovascular system and thus CVDs are needed.

\section{Abbreviations}

ANOVA: Analysis of variance; CVDs: Cardiovascular diseases; HF: Heart failure; RI: Rainfall index

\section{Declarations}

\section{Ethics approval and consent to participate}

Before the start of the study, an ethical clearance was obtained from the Regional Ethical Committee for Centre region's representation of the Cameroonian National Ethical Committee for Research in Human Health (Reference number: CE N-783-/CRERSHC/2019). Furthermore, this study was conducted in accordance with the ethical principles found in the 1964 Declaration of Helsinki and its later amendments. Inform consent was not request for this retrospective study, and data were handled anonymously.

\section{Consent for publication}

Not applicable

\section{Availability of data and materials}

The datasets generated during and/or analyzed during the current study are available from the corresponding author on reasonable request.

\section{Competing interests}

None 


\section{Funding}

None

\section{Authors' contributions}

CNNG: Concept/design, Data analysis/interpretation, Drafting article, Critical revision of article, Approval of article; ARAE: Data collection, critical revision of article, approval of article; GSW: Data analysis/interpretation, Drafting article, Critical revision of article, Approval of article, Statistics; DPTN: Data analysis/interpretation, Drafting article, Critical revision of article, Approval of article, Statistics; JB: Critical revision of article, Approval of article; LKM: Critical revision of article, Approval of article; SNA: Critical revision of article, Approval of article; BH: Critical revision of article, Approval of article; APM: : Concept/design, Supervision, Critical revision of article, Approval of article. All authors have read and approved the manuscript.

\section{Acknowledgements}

None

\section{References}

1. WHO. Cardiovascular diseases (CVDs) [Internet]. 2017 [cited 2020 Jun 4]. Available from: https://www.who.int/news-room/fact-sheets/detail/cardiovascular-diseases-(cvds).

2. Ziaeian B, Fonarow GC. Epidemiology and aetiology of heart failure. Vol. 13, Nature Reviews Cardiology. Nature Publishing Group; 2016. p. 368-78.

3. Metra M, Teerlink JR. Heart failure. Vol. 390, The Lancet. Lancet Publishing Group; 2017. p. 1981-95.

4. Agbor VN, Essouma M, Ntusi NAB, Nyaga UF, Bigna JJ, Noubiap JJ. Heart failure in sub-Saharan Africa: A contemporaneous systematic review and meta-analysis. Int J Cardiol. 2018 Apr 15;257:207-15.

5. Diaz A, Ciocchini C, Esperatti M, Becerra A, Mainardi S, Farah A. Precipitating factors leading to decompensation of chronic heart failure in the elderly patient in South-American community hospital. J Geriatr Cardiol. 2011;8(1):12-4.

6. Fares A. Winter cardiovascular diseases phenomenon. N Am J Med Sci. 2013;5(4):266.

7. Akintoye E, Briasoulis A, Egbe A, Adegbala O, Alliu S, Sheikh M, et al. Seasonal variation in hospitalization outcomes in patients admitted for heart failure in the United States. Clin Cardiol. 2017 Nov 1;40(11):1105-11.

8. Gibelin P. Météo et saisons influencent-elles notre cœur? Vol. 44, Presse Medicale. Elsevier Masson SAS; 2015. p. 821-7.

9. Ponikowski P, Voors AA, Anker SD, Bueno H, Cleland JGF, Coats AJS, et al. 2016 ESC Guidelines for the diagnosis and treatment of acute and chronic heart failure. Eur Heart J. $2016 \mathrm{Jul}$ 14;37(27):2129-200. 
10. Assongmo T. Les quartiers marginaux de l'agglomération de Yaoundé: logique de constitution et problèmes d'aménagement. http://www.theses.fr. 2002 Jan 1.

11. Boombhi J, Moampea M, Kuate L, Menanga A, Hamadou B, Kingue S. Clinical Pattern and Outcome of Acute Heart Failure at the Yaounde Central Hospital. OALib. 2017 Mar 2;04(03):1-8.

12. Keates AK, Mocumbi AO, Ntsekhe M, Sliwa K, Stewart S. Cardiovascular disease in Africa:

Epidemiological profile and challenges. Vol. 14, Nature Reviews Cardiology. Nature Publishing Group; 2017. p. 273-93.

13. Ansa V, Ekott J, Essien I, Bassey E. Seasonal variation in admission for heart failure, hypertension and stroke in Uyo, South-Eastern Nigeria. Ann Afr Med. 2008;7(2):62.

14. Sun Z. Cardiovascular responses to cold exposure. Front Biosci - Elit. 2010 Jan 1;2 E(2):495-503.

15. Liang S, Macinko J, Yue D, Meng Q. The impact of the health care workforce on under-five mortality in rural China. Hum Resour Health. 2019 Mar 18;17(1):21.

\section{Figures}

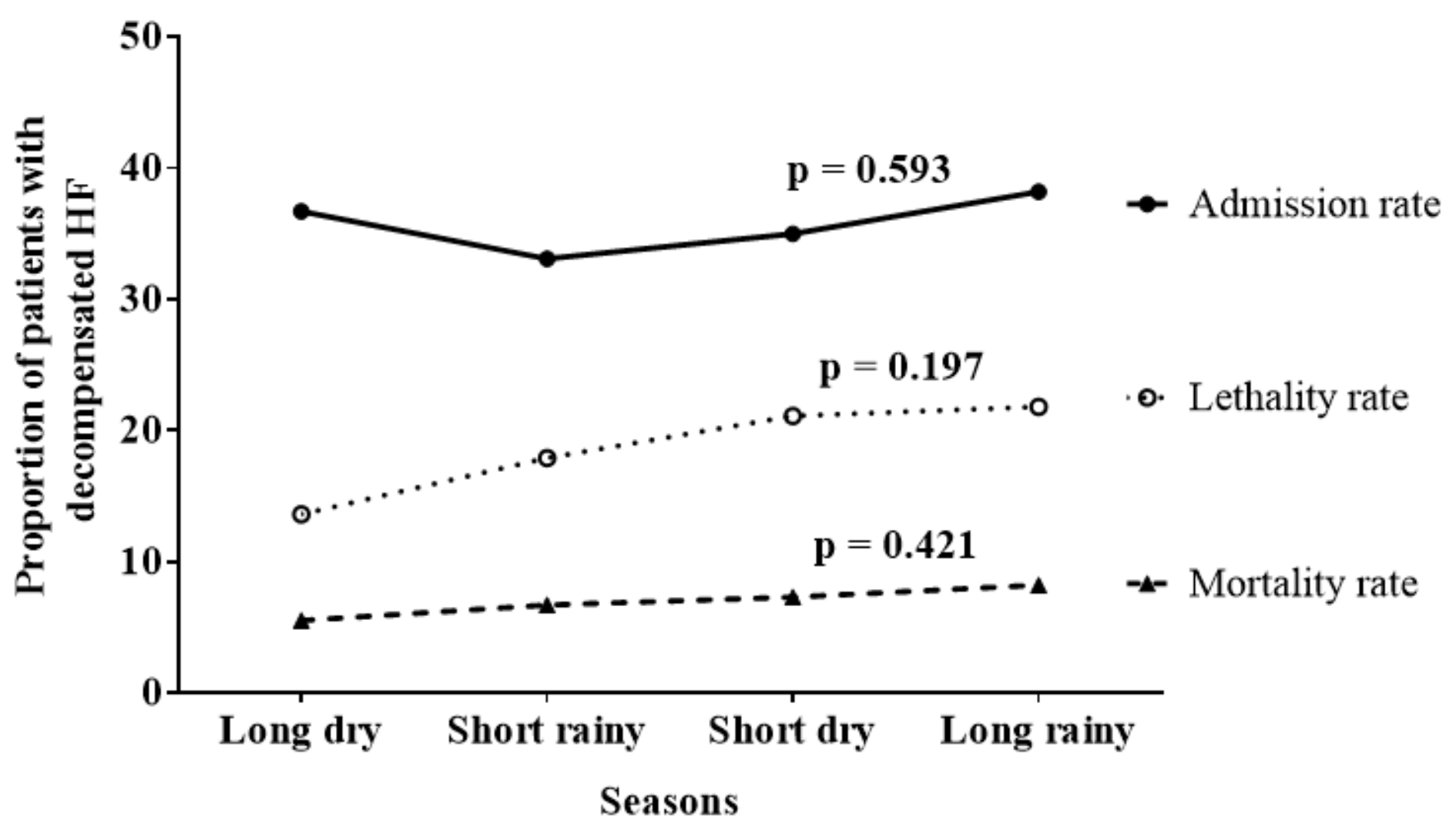

Figure 1

Description of seasonal variation of mortality, lethality and admission rates of decompensated HF during the study period. Admission rate $=$ (Number of patients admitted for decompensated HF $/$ total number of patients admitted during the period); Lethality rate $=$ (Number of deaths from decompensated HF / total 
number of patients admitted for decompensated HF during the period); Mortality rate $=$ (Number of deaths from decompensated HF / total number of patients admitted during the period). 